\title{
Evolution of the Parvalbumin Genes in Teleost Fishes after the Whole-Genome Duplication
}

\author{
Subham Mukherjee ${ }^{1,2}$, Oldřich Bartoš ${ }^{3}$, Kamila Zdeňková ${ }^{4}$, Petr Hanák ${ }^{5}$, Petra Horká ${ }^{1}$ (D) \\ and Zuzana Musilova ${ }^{6, * \mathbb{D}}$
}

1 Institute for Environmental Studies, Faculty of Science, Charles University, Benátská 2, 12801 Prague, Czech Republic; subham.mukherjee@natur.cuni.cz (S.M.); petra.horka@natur.cuni.cz (P.H.)

2 Department of Chemistry, Biochemistry and Food Microbiology, Food Research Institute Prague, Radiová 1285/7, 10231 Prague, Czech Republic

3 Military Health Institute, Military Medical Agency, Tychonova 1, 16001 Prague, Czech Republic; bartos@iapg.cas.cz

4 Department of Biochemistry and Microbiology, University of Chemistry and Technology, Prague, Technická 5 , 16628 Prague, Czech Republic; kamila.zdenkova@vscht.cz

5 Department of Molecular Biology of Cancer, Institute of Experimental Medicine, Academy of Sciences of the Czech Republic, Videnska 1083, 14200 Prague, Czech Republic; petr.hanak@iem.cas.cz

6 Department of Zoology, Faculty of Science, Charles University, Vinicna 7, 12844 Prague, Czech Republic

* Correspondence: zuzana.musilova@natur.cuni.cz

check for updates

Citation: Mukherjee, S.; Bartoš, O.; Zdeňková, K.; Hanák, P.; Horká, P.; Musilova, Z. Evolution of the Parvalbumin Genes in Teleost Fishes after the Whole-Genome Duplication. Fishes 2021, 6, 70. https://doi.org/ $10.3390 /$ fishes 6040070

Academic Editor: Eric Hallerman

Received: 31 October 2021

Accepted: 23 November 2021

Published: 1 December 2021

Publisher's Note: MDPI stays neutral with regard to jurisdictional claims in published maps and institutional affiliations.

Copyright: (c) 2021 by the authors. Licensee MDPI, Basel, Switzerland. This article is an open access article distributed under the terms and conditions of the Creative Commons Attribution (CC BY) license (https:/ / creativecommons.org/licenses/by/ $4.0 /)$.

\begin{abstract}
Parvalbumin is considered a major fish allergen. Here, we report the molecular evolution of the parvalbumin genes in bony fishes based on 19 whole genomes and 70 transcriptomes. We found unexpectedly high parvalbumin diversity in teleosts; three main gene types (pvalb- $\alpha$, pvalb- $\beta 1$, and pvalb- $\beta 2$, including oncomodulins) originated at the onset of vertebrates. Teleosts have further multiplied the parvalbumin gene repertoire up to nine ancestral copies-two copies of $p v a l b-\alpha$, two copies of pvalb- $\beta 1$, and five copies of pvalb- $\beta 2$. This gene diversity is a result of teleost-specific wholegenome duplication. Two conserved parvalbumin genomic clusters carry pvalb- $\beta 1$ and $\beta 2$ copies, whereas pvalb- $\alpha$ genes are located separately in different linkage groups. Further, we investigated parvalbumin gene expression in 17 tissues of the common carp (Cyprinus carpio), a species with 21 parvalbumin genes in its genome. Two pvalb- $\alpha$ and eight pvalb- $\beta 2$ copies are highly expressed in the muscle, while two alternative pvalb- $\alpha$ copies show expression in the brain and the testes, and pvalb- $\beta 1$ is dominant in the retina and the kidney. The recent pairs of muscular pvalb- $\beta 2$ genes show differential expression in this species. We provide robust genomic evidence of the complex evolution of the parvalbumin genes in fishes.
\end{abstract}

Keywords: parvalbumin; fish; molecular evolution; allergenicity; fish allergy; genome duplication; gene expression; isoform; oncomodulin; pvalb gene

\section{Introduction}

Parvalbumins are proteins from the calmodulin family, found mostly in the muscular tissues in vertebrates, and they are also considered to be major fish allergens, which cause an IgE-mediated food hypersensitivity reaction in sensitive consumers [1]. As an example of the diversified gene family, parvalbumin genes (referred to as pvalb) also carry traces of the ancient genomic duplications in eukaryotes, vertebrates, and teleost fishes [2-4]. At the same time, the parvalbumin gene (including its intron) is an interesting marker that is used to identify fish species, or for phylogenetic studies [5-8].

Parvalbumins are small acidic proteins ( $\mathrm{pI} 3-5)$ with high $\mathrm{Ca}^{2+}$ binding affinity, specific to vertebrates, mostly comprising 108-109 amino acids with a molecular mass of $12 \mathrm{kDa}[9,10]$, and were first crystallized from the carp muscle by Henrotte in 1952 [11]. Parvalbumin plays an important role in the relaxation of fast-twitch skeletal muscle fibers, and the protein is found in extreme abundance in fish muscles [12-14]. In a lower amount, 
parvalbumins are also found in other tissues, such as the central nervous system, retina, kidney, testis, and several endocrine glands [15-21]. In bony fishes, the quantity of parvalbumin protein in the muscle generally varies among species, and the overall amount of parvalbumin protein also corresponds to variable allergenicity in fishes [22-24]. A different amount of parvalbumin has also been detected in the dark and light muscles of fishes $[25,26]$.

General cross-reactivity in fish-allergic individuals is caused by the structural homology of parvalbumins in various fish species [27], and many fish species have been reported for multiple " $\beta$-parvalbumin isoforms" [28-31], or, in general, multiple parvalbumin genes have been found, such as nine pvalb genes in zebrafish [9] or numerous "haplotypes" in salmon [32]. The observed variability and somewhat confusing findings speak for more complex evolutionary patterns based on multiple pralb gene copies.

Parvalbumin belongs to the calmodulin protein family with four EF-hand domains (calcium binding domains), and gene duplication events have led to the evolution of these genes in eukaryotes $[2,33,34]$. Traditionally, two parvalbumin types (often referred to as "isoforms") were originally reported in vertebrates—alpha and beta, differing slightly in amino acid sequence length, as well as in the $\mathrm{pI}$ of the protein [9,35]. Later, two beta types ( $\beta 1$ and $\beta 2$ ) were clearly identified [3,4], and both of them also include genes labelled as oncomodulins in other vertebrates (thanks to their high activity in tumor cells [3]). The origin of the three main pvalb types has been attributed to the vertebrate ancestor [2,4], and one or two vertebrate-specific whole-genome duplication(s), possibly contributing to the gene diversity of pralb.

Whole-genome duplications provide a substrate for subsequent functional and morphological innovation in evolution [36-38]. The ancestor of vertebrates experienced two rounds of whole-genome duplication (1R and $2 R$ ), which led to quadruplication of the genome content [39]. Later in evolution, the ancestor of bony fishes diverged to give rise to lobe-finned fishes, from which mammals and other tetrapods evolved, and to ray-finned fishes, from which teleosts later evolved [40]. The ancestor of teleosts then underwent an additional teleost-specific whole-genome (3R or TSGD) duplication $~ 350$ million years ago [41], and its genome content was doubled once again. Traces of the whole-genome duplications are still detectable in some conserved gene families, such as Hox genes; a lancelet (a non-vertebrate representative diverged prior to the vertebrate-specific duplications) possesses one Hox gene cluster, while mammals (and other tetrapods) possess four clusters, and teleosts (e.g., zebrafish, medaka, pufferfish, or eels) possess up to eight Hox gene clusters in their genome [42-44]. Apart from the ancient gene duplications, several lineages of teleosts have undergone additional gene duplications, such as in the ancestor of Salmoniformes ( 80 mya [45]), in Cyprinidae (8.2 mya [46]), or in sturgeons (more than 180 mya [47]). Here, we aim to assign the parvalbumin diversity of teleosts to teleost-specific whole-genome duplication, and to investigate whether a cluster duplication pattern is still detectable in the teleost genomes.

The dynamics and fate of the genes after the whole-genome duplications have been widely discussed, as most of the genes are lost and only a subset of the paralogous genes is then later preserved $[48,49]$. After duplication, one of the two gene copies may be silenced, pseudogenized, and eventually lost. Less commonly, both gene copies are maintained, and, thanks to the subsequent mutations, one of them may later acquire a novel function, or its original function may be modified. The evolution of opsin genes in teleosts [50-52], or the antifreeze protein gene in Antarctic fishes, evolved from the protease gene, are examples of such a case [53]. Genomic rearrangements can also alter the position and appearance of the gene clusters in recent species when compared to the ancestral genomic architecture.

The parvalbumin gene repertoire in bony fishes is more diverse than in other vertebrates. Here, we aim to provide an evolutionary reconstruction of the fish parvalbumins using whole genomic and transcriptomic data. The main goal of this study is to provide a comprehensive genomic reference for future studies on the parvalbumin gene. Further, we also investigate the number of parvalbumin copies and specifically focus on species 
with additional whole-genome duplications, such as the common carp (Cyprinus carpio), Atlantic salmon (Salmo salar), and sterlet (Acipenser ruthenus).

\section{Materials and Methods}

\subsection{Genomic and Transcriptomic Data Set}

In this study, we analyzed 19 genomes of vertebrates (13 of ray-fined fishes) to screen for the parvalbumin gene repertoire (Table 1). We further analyzed parvalbumin gene expression based on 70 transcriptomes of 17 different tissues from the common carp (Table S1). For the phylogenetic analysis, we also used additional single parvalbumin sequences available on the GenBank database. The data were downloaded from NCBI database, the list of genomes with the accession numbers is available in Table 1, the list of common carp transcriptomes, including the accession numbers and the details of the expression results, is found in Supplementary Table S1, and the accession numbers of the single parvalbumin sequences are provided directly in Figures 1 and 2. The details of all analyses are described in the following sections.

Table 1. Selected genomes analyzed in this study with NCBI database accession numbers and the number of pvalb genes.

\begin{tabular}{|c|c|c|c|c|c|}
\hline Scheme 1. & GenBank Accession Number & Total pvalb Genes & pvalb- $\alpha$ & pvalb- $\beta 1$ & pvalb- $\beta 2$ \\
\hline \multicolumn{6}{|l|}{ other vertebrates: } \\
\hline Sea lamprey (Petromyzon marinus) & GCA_010993605.1 & $1+6^{1}$ & 0 & 0 & 0 \\
\hline Ghostshark (Callorhinchus milii) & GCA_018977255.1 & 5 & 1 & 1 & 3 \\
\hline African clawed frog (Xenopus laevis) & GCA_017654675.1 & 28 & 3 & 3 & 22 \\
\hline Chicken (Gallus gallus) & GCA_016699485.1 & 4 & 1 & 1 & 2 \\
\hline Human (Homo sapiens) & GCA_000001405.28 & 3 & 1 & 2 & 0 \\
\hline Mouse (Mus musculus) & GCA_000001635.9 & 2 & 1 & 1 & 0 \\
\hline \multicolumn{6}{|l|}{ ray-fined non-teleost fishes: } \\
\hline Senegal bichir (Polypterus senegalus) & GCA_016835505.1 & 8 & 1 & 1 & 6 \\
\hline Sterlet (Acipenser ruthenus) & GCA_010645085.1 & 12 & 1 & 3 & 8 \\
\hline Spotted gar (Lepisosteus oculatus) & GCA_000242695.1 & 7 & 2 & 0 & 5 \\
\hline \multicolumn{6}{|l|}{ teleost fishes: } \\
\hline European eel (Anguilla anguilla) & GCA_013347855.1 & 9 & 2 & 2 & 5 \\
\hline Elephantfish (Paramormyrops kingsleyae) & GCA_002872115.1 & 9 & 2 & 2 & 5 \\
\hline Common carp (Cyprinus carpio) & GCA_018340385.1 & 21 & 4 & 4 & 13 \\
\hline Zebrafish (Danio rerio) & GCA_000002035.4 & 9 & 2 & 2 & 5 \\
\hline Northern pike (Esox lucius) & GCA_011004845.1 & 7 & 2 & 2 & 3 \\
\hline Atlantic salmon (Salmo salar) & GCA_000233375.4 & 22 & 4 & 4 & 14 \\
\hline Atlantic cod (Gadus morhua) & GCA_902167405.1 & 9 & 2 & 2 & 5 \\
\hline Pacific bluefin tuna (Thunnus orientalis) & GCA_009176245.1 & 9 & 2 & 2 & 5 \\
\hline Gilthead seabream (Sparus aurata) & GCA_900880675.1 & 9 & 2 & 2 & 5 \\
\hline Nile tilapia (Oreochromis niloticus) & GCA_001858045.3 & 8 & 2 & 2 & 4 \\
\hline
\end{tabular}

${ }^{1}$ Sea lamprey has seven pvalb-like/calmodulin-like genes not shared with other vertebrates.

\subsection{Parvalbumin Genomic Repertoire and Phylogenetic Reconstruction of the Parvalbumin Genes}

We used a reference parvalbumin gene set, which was composed of zebrafish (Danio rerio; nine parvalbumin genes; GCA_000002035.4), northern pike (Esox lucius; seven genes; GCA_011004845.1), and Nile tilapia (Oreochromis niloticus; eight genes; GCA_001858045.3.) comprising 24 parvalbumin gene sequences in total. This reference set was used to extract parvalbumin genes from the genomes and assemblies downloaded from the NCBI database (Table 1). The downloaded genomes were mapped against the reference data set by Geneious Prime software (V2021.1.1) with medium sensitivity settings. The mapped scaffolds/chromosomes were then manually screened for the number, orientation and physical position of the parvalbumin genes to illustrate the organization of the genes in cluster(s). The parvalbumin gene sequences from each genome were then extracted for the purpose of the phylogenetic analysis. After extraction, the sequences were aligned using MAFFT alignment (MAFFT v7.450 [54,55]). Phylogenetic analyses of a total of 236 parvalbumin gene sequences were carried out using a Bayesian framework with the parallel version of MrBayes 3.2.7 [56,57]. We applied a molecular clock analysis following Modrell et al., 2017 [4], as implemented in the MrBayes plugin in Geneious, to infer the 
phylogeny. A 'mixed' substitution model with independent gamma rates was used for 20 million generations, sampling every 1000 generations and discarding the first $20 \%$ as burn-in. The resulting annotated consensus tree was subsequently inspected in FigTree [58]. The number of generations was sufficient as the $-\ln L$ values reached the plateau shape. We used human calmodulin genes as an outgroup for the molecular clock analysis (GenBank acc. no.: M19311.1, NM_006888.6 and NM_005184.4).

\subsection{Transcriptomic Analysis in the Common Carp Tissues}

The genome of common carp (Cyprinus carpio) contains 21 parvalbumin genes, of which 19 have a unique sequence (two pairs of genes show an identical sequence despite their different locations in the genome). This set of genes has been used as a reference for transcriptome analyses and the reconstruction of expression profiles. RNAseq data used in this study were downloaded from public NCBI SRA archives [59], the accession numbers are provided in Supplementary Table S1. All data were filtered for potential PhiX contamination and subsequently subject to adapter and quality trimming using BBduk.sh from the BBsuite (tbo tpe $\mathrm{ktrim}=\mathrm{rk}=21$ mink $=9$ hdist $=1$ qtrim $=\mathrm{rl}$ trimq $=15$ minlength $=36$ trimpolya $=5$ ) [60]. To estimate expression levels of individual genes, we utilized the Salmon tool [61]. To minimize spurious mappings and to obtain relevant TPM (transcripts per million) estimates, we built its index using whole genomic reference (GCA_000951615.2) in combination with slightly modified full transcriptomic reference (GCF_018340385.1). We replaced all parvalbumin genes from the transcriptomic reference by a manually curated set of 21 parvalbumin genes. Using such an index we obtained quantification of individual transcripts (-1 "IU" -validateMappings). To validate both the methodology and (and most importantly) the quality of individual data samples, we also utilized four marker genes with virtually stable and predictable behavior throughout individual tissues [62]. These reference markers are 40S (acc. no. XM_042745936.1), RPL7 (XM_042742284.1), RPS5 (XM_042771625.1) and RPS18 (XM_042776097.1). Expression quantification data were further processed and analyzed in the R environment [63]. We constructed a heatmap using the palette from the R package "colorspace" [64].

\section{Results and Discussion}

We reconstructed the evolutionary history of parvalbumin genes based on the data of 19 genomes of the teleost fish, ray-finned fish, and vertebrate representatives. We found unexpected diversity of the parvalbumin genes in teleosts (up to 22 different pvalb genes in Atlantic salmon), and we showed evidence of the role of the ancestral geneand whole-genome duplications on the parvalbumin gene repertoire. Finally, based on 70 transcriptomes of common carp tissues, we identified the tissue-specific expression of 21 different parvalbumin copies in carp.

\subsection{Parvalbumin Gene Repertoire in Teleost Fishes}

We report on the higher diversity of parvalbumin genes in teleost fishes compared to other vertebrate groups (except for amphibians; Table 1, and Figures 1 and 2). In total, the selected teleost fish species possess between seven (northern pike; Esox lucius) and 22 (Atlantic salmon; Salmo salar) parvalbumin genes in their genome (Figure 3). We confirm the presence of three ancestral parvalbumin gene types (pvalb- $\alpha, p v a l b-\beta 1$, and pvalb- $\beta 2$; named as per Modrell et al., 2017 [4]), which emerged at the onset of vertebrates (Figures 1 and 2). Later in evolution, teleosts further duplicated their parvalbumin gene repertoire up to nine (at least) ancestral copies; the teleost ancestor most likely had two copies of $p v a l b-\alpha$, two copies of $p v a l b-\beta 1$, and five copies of $p v a l b-\beta 2$ genes (Figures 1 and 2). Naturally, not all species of teleosts have preserved all the copies until recently, and, on the other hand, some copies have been further multiplied by additional gene duplications. The diversity of the genes within these three parvalbumin types among non-fish vertebrates seems to also be variable (ghost shark: pvalb- $\alpha=1$, pvalb- $\beta 1=1$, pvalb- $\beta 2=3$; chicken = 1, 1, 2; human = 1, 2, 0 ; mouse $=1,1$, 0 ; clawed frog = 3, 3, 22, 
respectively) and, interestingly, mammals (human + mouse) seem to have lost the pvalb- $\beta 2$ gene completely (Figures 1 and 2). Contrarily, in teleost fishes, the pvalb- $\beta 2$ gene is the most diversified, with six ancestral copies, and the Atlantic salmon possesses up to 14 copies of poalb- $\beta 2$ (Figures 3 and 4).

While the three ancestral parvalbumin gene types (pvalb- $\alpha, p v a l b-\beta 1$, and $p v a l b-\beta 2)$ are well supported (Figure 1), and also include vertebrate oncomodulins (belonging to both the pvalb- $\beta 1$ and pvalb- $\beta 2$ gene types), the mutual phylogenetic relationships among these types remain uncertain. We observe a topology ((pvalb- $\alpha,[p v a l b-\beta 1+p v a l b-\beta 2])$, with low support of 0.609), which is an alternative to that identified by Modrell et al., 2017 [4] ((pvalb- $\beta 1,[$ pvalb- $\alpha+$ pvalb- $\beta 2])$, with low support of 0.52$)$ or Climer et al., 2019 [3] (the same topology as Modrell et al., 2017 [4]; bootstrap support of only 17). Based on the current data, it is, therefore, not possible to tell which type of parvalbumin gene is the most ancestral and which of the genes are more recent sister copies.

\subsection{Whole-Genome Duplications Have Boosted Parvalbumin Gene Diversity}

Whole-genome duplication doubles the genetic content and, as such, it gives a substrate for evolution and selection to act on [36]. The vertebrate ancestor has undergone two rounds of whole-genome duplication in the past, and these events are sometimes considered to be responsible for vertebrate evolutionary success [39]. Teleost fishes, on top of this, have experienced an additional whole-genome duplication [41], resulting in up to eight ancestral paralogous (=ohnologous) genes/clusters in the genome, a pattern that is still noticeable on some very conserved gene families (such as developmental Hox genes [44] and hemoglobins [65]), or detected in single genes for the olfactory marker protein $(O M P)$ [66] or melanoma cell adhesion molecule (mcam) [67]. Accordingly, we detect conservation of the two main parvalbumin clusters throughout teleosts, which we conclude causes the teleost-specific whole-genome duplication (Figure 3). The genomic organization of the parvalbumin genes shows a conserved pattern across most of the 11 studied teleost species, while it is not found in three non-teleost fishes (Figure 3). In fact, six species have the exact same number of parvalbumin genes and the same position in the genome (two pvalb- $\alpha$, two pvalb- $\beta 1$, and five pvalb- $\beta 2$ genes). In these species, the parvalbumin genes are organized in four genomic regions (Figure 3 ). All the pvalb- $\beta$ genes are organized in the two main pvalb-beta clusters (each with one pvalb- $\beta 1$ and multiple pvalb- $\beta 2$ genes), whereas the two pvalb- $\alpha$ genes are always located separately, although one of them is often on the same chromosome as, but not in close proximity to, the beta cluster (Figure 3). Only species that experienced a recent genomic duplication, such as the common carp or Atlantic salmon, have more genomic clusters with parvalbumins in their genomes, and we found traces of the ancestral teleost-specific duplication, as well as the more recent lineage-specific duplication, in both species. The northern pike (Esox lucius), on the other hand, reduced the number of pvalb genes in its genome and lost two pvalb- $\beta 2$ genes, and the Nile tilapia (Oreochromis niloticus) lost one pvalb- $\beta 2$ gene. Finally, the sterlet (Acipenser ruthenus), a non-teleost fish species, has experienced sturgeonspecific duplications, and, therefore, it carries two genomic pvalb clusters, which have evolved independently of the teleost-specific duplication (Figure 3).

Here, we also focus, in more detail, on the species with one of the highest number of parvalbumin genes among teleosts, which is the common carp, with 21 parvalbumin genes in its genome (four pvalb- $\alpha$ genes, four pvalb- $\beta 1$ genes, and 13 pvalb- $\beta 2$ genes). The common carp experienced an additional lineage-specific whole-genome duplication 8.2 million years ago [46], and most of its parvalbumin duplicates have still been preserved in the genome and can be observed in the phylogenetic tree as sister sequences (Figures 1 and 2). We have described ten genomic regions where parvalbumin genes can be found and we have detected the sister duplicates, which have resulted from this carp genome duplication (Figure 3). 


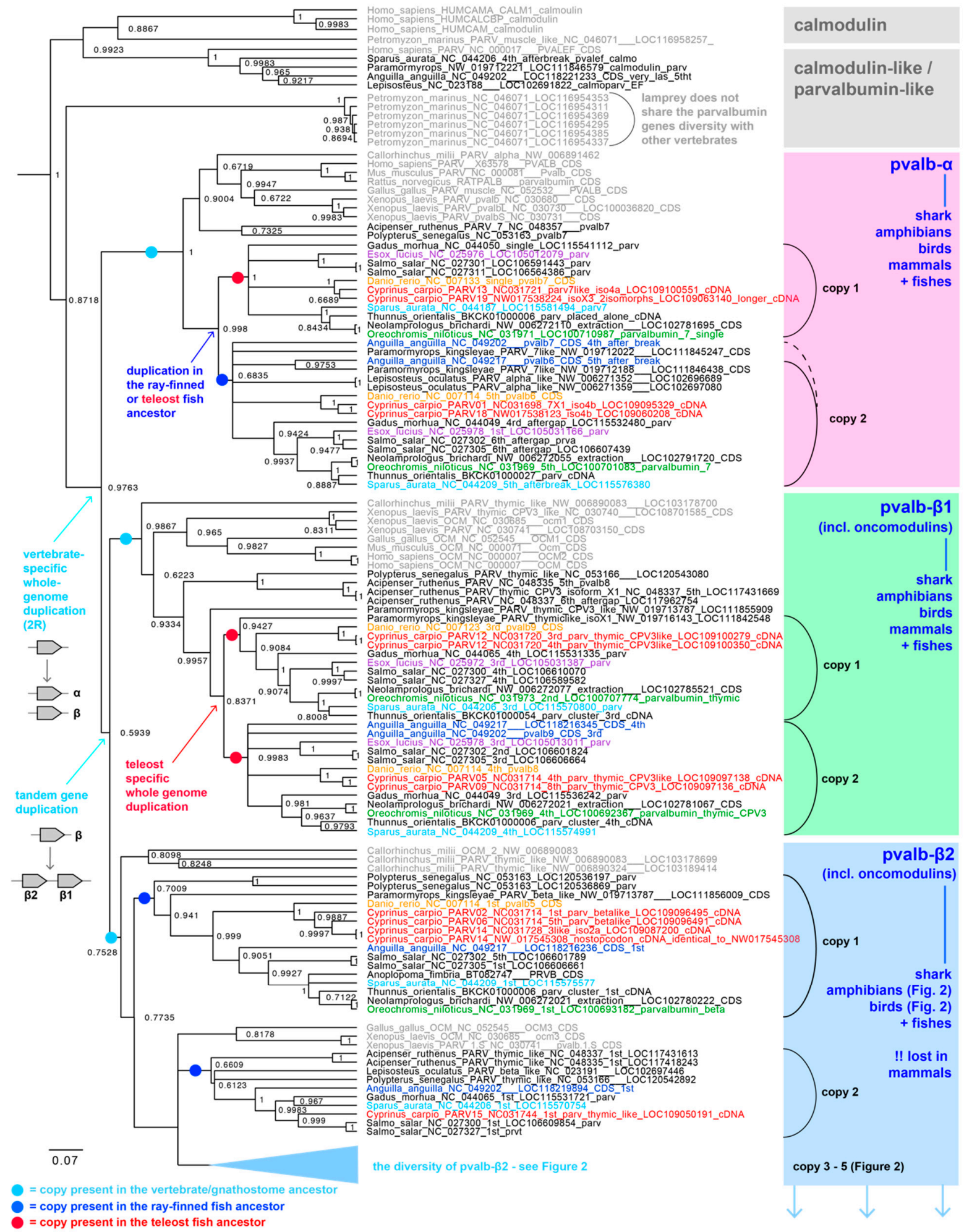

Figure 1. Parvalbumin phylogenetic gene tree reconstructed by the molecular clock analysis in MrBayes. Three main types of parvalbumin genes, parvalbumin alpha (pvalb- $\alpha$; highlighted by purple), parvalbumin beta1 (pvalb- $\beta 1$; highlighted by green) and parvalbumin beta2 (pvalb- $\beta 2$; highlighted by blue), have existed in the vertebrate ancestor and possibly have emerged by the vertebrate-specific whole-genome duplication (most likely $2 \mathrm{R}$ after the split of lampreys) and a subsequent tandem gene duplication. The pvalb genes have further diversified in the teleost fishes. Teleosts have multiple ancestral duplicates of the following genes: two different copies of $p v a l b-\alpha$, two different copies of $p v a l b-\beta 1$ and five copies of $p v a l b-\beta 2$ (for details on pvalb- $\beta 2$ see Figure 2). 


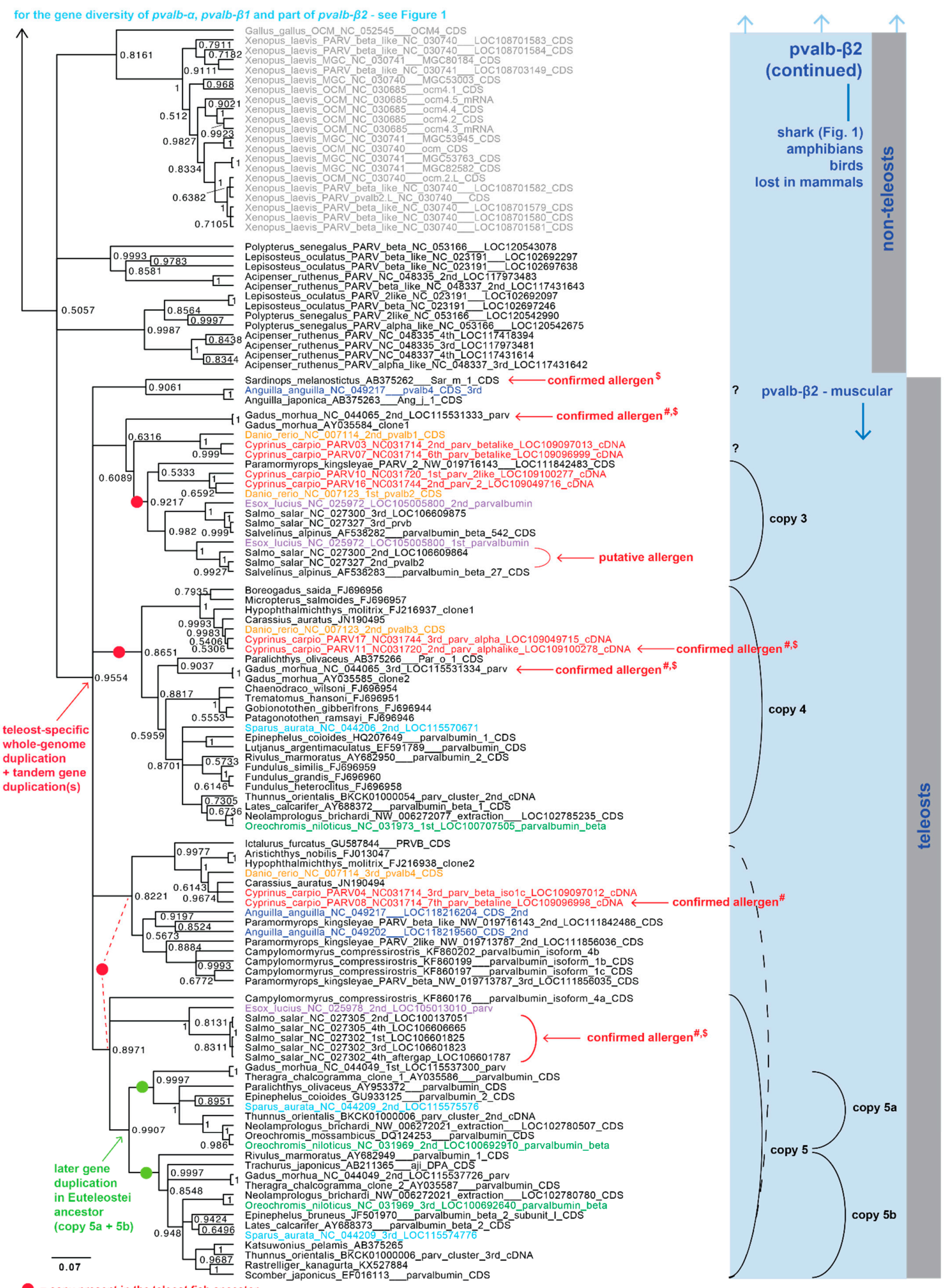

= copy present in the teleost fish ancesto

= copy present in the Euteleostei fish ancestor

Figure 2. Parvalbumin phylogenetic gene tree-part of the pvalb- $\beta 2$ gene type (continued from Figure 1). Pvalb- $\beta 2$ is the most diversified parvalbumin gene type in teleosts with five ancestral copies present in the teleost ancestor (two of them 
most likely even earlier, in the vertebrate ancestor). One of the copies (copy 5) duplicated later in the evolution of euteleost fishes. Some species show multiple duplicates of some copy types either as a result of the species/lineage-specific gene duplication, or as an outcome of an additional whole-genome duplication (such as the common carp, Atlantic salmon or sterlet). Confirmed allergen copies in carp and salmon are highlighted, allergenicity confirmed by \# Swoboda et al., 2002 [1], Lindstrom et al., 1996 [30], and Van Do et al., 2005 [28] and \$ = the official www.allergen.org database (accessed on 15 October 2021) as per Kuehn et al., 2014 [23]. Non-ray-finned fish species names are shown in grey, ray-finned fish in black or in color, red = common carp (Cyprinus carpio), green = Nile tilapia (Oreochromis niloticus), orange = zebrafish $($ Danio rerio), purple = northern pike (Esox lucius), dark blue = European eel (Anguilla anguilla) and light blue = gilthead seabream (Sparus aurata).

\subsection{Gene Expression of Parvalbumin Genes in the Common Carp (Cyprinus carpio)}

New gene copies that emerged after gene duplication may serve as a "substrate" for gene subfunctionalization or neofunctionalization, i.e., acquisition of a new function, that is, after the genes accumulate enough mutations, they may be differentially involved in its function, and are, therefore, often differentially expressed. The main role of parvalbumin is to reversibly bind cations, and, hence, to cause muscle relaxation [12], although it has different functions in other tissues as well [3,15-19]. The involvement of different parvalbumins has been detected in relation to sensory systems; for example, two different beta parvalbumins show signs of subfunctionalization in the ampullary organs and neuromasts of paddlefish (Polyodon spathula [4]). Similarly, two parvalbumins are differentially expressed in the Corti organ in rats [16]. Generally, differential gene expression of parvalbumin is also found in the electric organ of mormyrids fishes [68], in the muscles of the grass carp (Ctenopharyngodon idella; [69]), with a different growth rate, or it is linked to the pathophysiology of cognitive functions [70]. Its differential regulation has even been associated with very unrelated features, such as autism spectrum disorders in humans [71], or vocal learning in birds and humans [72].

We selected the common carp as a species with multiple parvalbumin genes, resulting from both ancient (vertebrate- and teleost-specific) and more recent (8.2 million years ago [46]) whole-genome duplications, and we have specifically checked the expression of the duplicates in 17 different tissues (Figure 4, Table S1). We took advantage of the available gene expression data in the GenBank database (data previously sequenced by ourselves, or other researchers; Table S1 with accession numbers and results). As expected, the highest parvalbumin gene expression is found in muscles (and skin), where two gene copies of pvalb- $\alpha$ and eight copies of pvalb- $\beta 2$ are highly abundant. Two different copies of pvalb- $\alpha$ are then dominantly expressed in the testes, and one copy of the pvalb- $\beta 1$ gene is dominant for retina and kidney expression (Figure 4). The pvalb- $\alpha$ gene is also dominantly expressed in the brain, including all four copies (i.e., the two copies found in the muscle, as well as the two copies found in the testes). Interestingly, the thymus seems to have the highest pvalb gene diversity, and the brain, testes, kidney, and retina seem to rely mostly, or partially, on different parvalbumin proteins than muscles (Figure 4). The youngest pvalb copies resulting from recent evolutionary whole-genome duplication generally keep the expression levels similar within the gene pairs, with minor differences in expression. Out of four pairs of pvalb- $\beta 2$ genes, we noticed differential expression between the members of two pairs in the muscle and skin (PARV03-07 and PARV10-16; Figure 4). To conclude, our study aims to report on the details of the subfunctionalization of pvalb genes after teleost-specific whole-genome duplication (as found between the two pvalb- $\alpha$ copies and two pvalb- $\beta 1$ copies, and also within multiple pvalb- $\beta 2$ copies), as well as on the differential expression of the more recent pvalb- $\beta 2$ copies in the muscle and skin. 


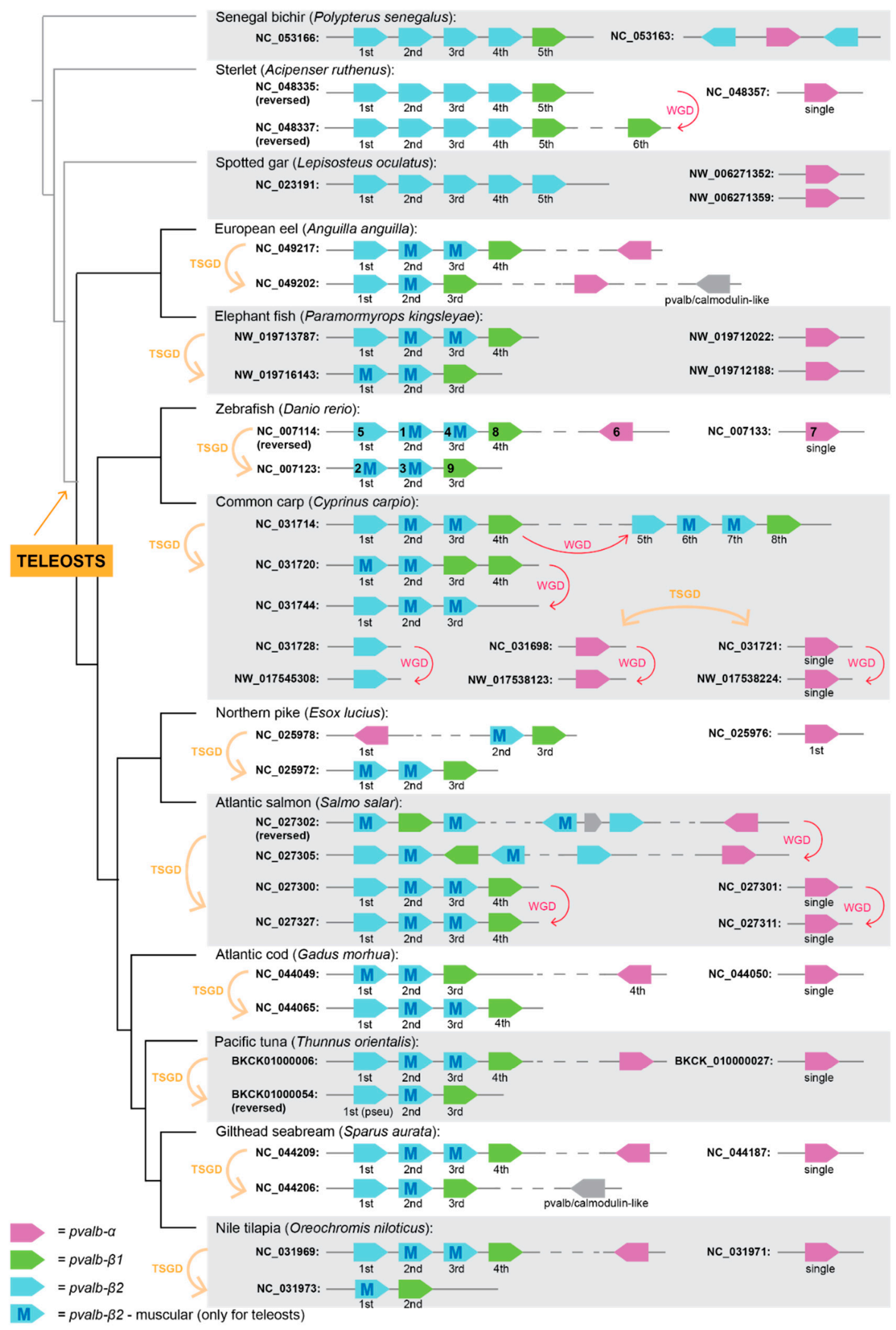

Figure 3. Synteny groups in selected species of the teleost fishes and a non-teleost outgroup. Parvalbumin genes found in the selected fish genomes are shown in their syntenic groups and colored by the parvalbumin gene type, i.e., parvalbumin alpha $(p v a l b-\alpha)$ in purple, parvalbumin beta 1/oncomodulin (pvalb- $\beta 1)$ in green, and parvalbumin beta 2 /oncomodulin (pvalb- $\beta 2$ ) in blue. The gene labels correspond to the names as presented in the phylogenetic tree (Figures 1 and 2 ). Orange arrow and the TSGD label mark the cluster originated from teleost-specific whole-genome duplication. Red arrow marks 
the syntenic groups or genes resulting from the recent whole genomic duplication (WGD) in carp (8.2 mya [46]), or older lineage-specific duplications in salmon ( $~ 80$ mya [45]) and sterlet ( $>180$ mya [47]).

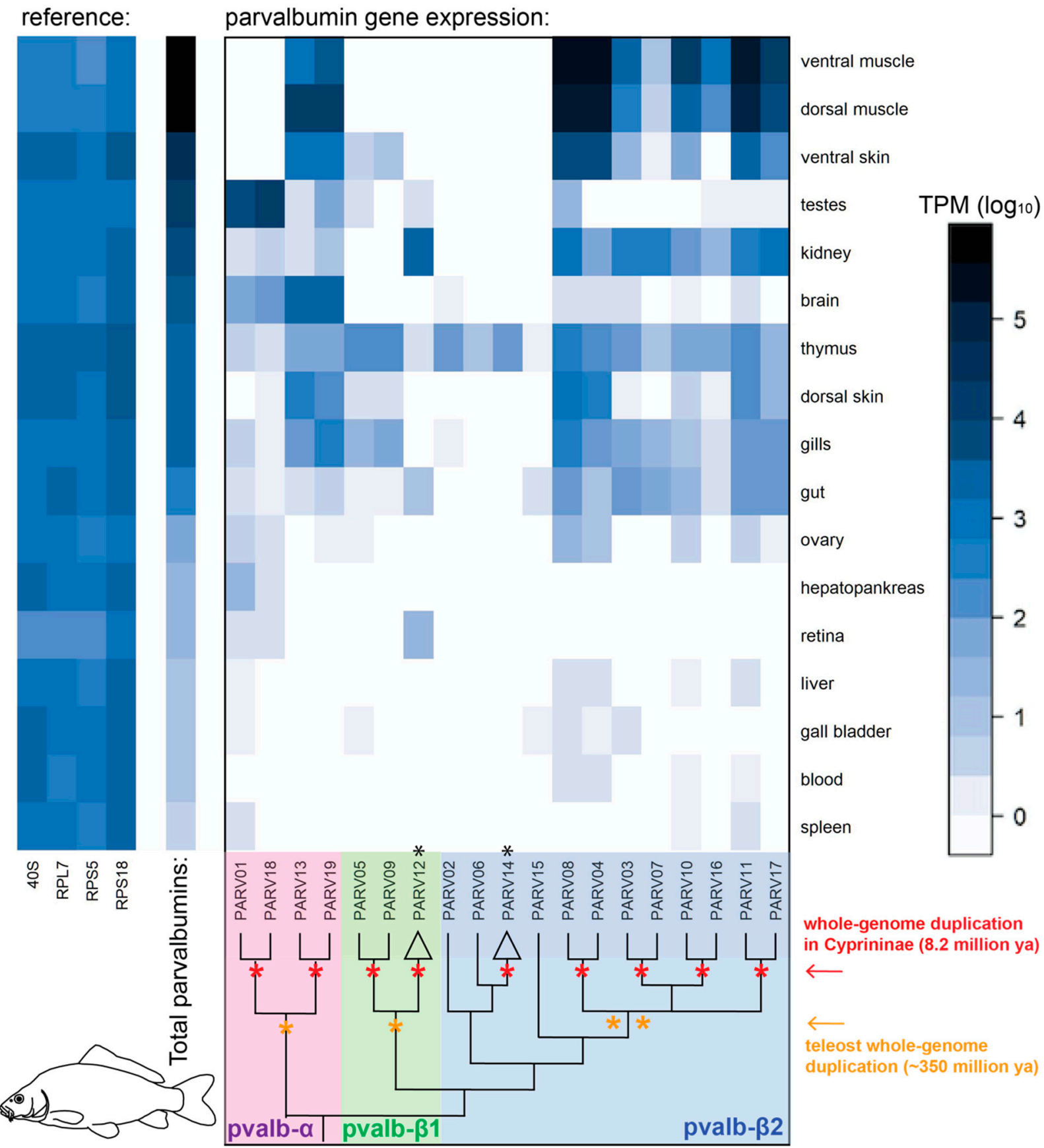

Figure 4. Heatmap of the parvalbumin gene expression in different tissues of the common carp (Cyprinus carpio). The teleost-specific whole-genome duplication provided genetic substrate for the subsequent subfunctionalization (or neofunctionalization) of the gene function as clearly observed in the pvalb- $\alpha$ copies (testes vs. muscle/skin expression) and pvalb- $\beta 1$ copies (thymus/gills vs. kidney/retina expression). The pattern within pvalb- $\beta 2$ is more complex, yet only a subset of the copies shows expression in muscle and skin. The reference genes and total level of expression (all parvalbumins) are shown on the left. The expression of particular parvalbumin gene copies is shown in the main heatmap panel (framed). The tissues are ordered by the level of total expression of all parvalbumins. The highest parvalbumin gene expression is found in muscles and skin, where two gene copies of $p v a l b-\alpha$ and eight copies of $p v a l b-\beta 2$ are highly abundant. Two different copies of pvalb- $\alpha$ are expressed in testes, and one copy of pvalb- $\beta 1$ gene is dominant in retina and kidney. The pvalb- $\alpha$ gene is also dominantly expressed in the brain including all four copies (i.e., the two found in muscles as well as the two found in 
testes). Orange star symbol marks the teleost-specific whole-genome duplication ( 350 million year ago; [41]) and the red star symbol marks the whole-genome duplication event within Cyprinidae (8.2 million year ago; [46]), which resulted in the enriched parvalbumin gene diversity in this species. Most gene duplicates have persisted in the genome after the duplication. Two of the gene copies (one within the pvalb- $\beta 1$ and one within the pvalb- $\beta 2$ gene type; marked by black star symbol) are identical to their sister copy and could not be distinguished in the gene expression analysis.

\subsection{Fish Allergenicity and the Muscle Parvalbumins}

We have specifically focused on the allergenic copies of the parvalbumin gene, and they all belong to the pvalb- $\beta 2$ type. Specifically, we have highlighted the reported allergenic copies known from the common carp (Cyprinus carpio), the Atlantic salmon (Salmo salar), and the Atlantic cod (Gadus morhua) (Figure 2). This allergenic muscular parvalbumin pvalb- $\beta 2$ type has proliferated in teleosts and has at least three ancestral copies (copy 3-5 in Figure 2), whereas it has been completely lost in mammals. Fish allergenicity is often studied with notion on the existence of multiple parvalbumins. While some studies focus on just a fraction of the detected dominant parvalbumins (e.g., two types in the common carp [24]), later studies often notice higher complexity of the parvalbumin in fish and refer to multiple "isoforms", such as eight isoforms in the common carp [73], or "high isoform complexity" in cod and mackerel [74]. Here, we conclude that the diversity of parvalbumin is technically not caused by the isoforms of the same gene (i.e., different products of alternative splicing or post-translational modifications), but rather by the presence of multiple gene copies of the parvalbumin genes in the genome (i.e., with different physical location), encoding for multiple parvalbumin protein types (Figure 3). The main goal of this study is, therefore, to provide genomic evidence and to help consider parvalbumin genetic complexity as a whole, which will subsequently facilitate more specific targeting of protein analyses in future studies.

\section{Conclusions}

The main goal of this study is to describe the parvalbumin gene complexity in rayfinned fishes based on genomic and transcriptomic evidence. Our study aims to serve as a comprehensive genomic overview, which will allow future studies to target and focus on the functional aspects of parvalbumin, including, for example, allergenicity, and its possible identification and diagnosis. We report on the high diversity of parvalbumin genes based on genomic data. We reconstructed the complex evolutionary history of the pvalb genes in vertebrates, with the main focus on teleost fishes. We used genomic evidence to identify the three main parvalbumin types in vertebrates (pvalb- $\alpha$, pvalb- $\beta 1$, and pvalb- $\beta 2$ ), and at least nine ancestral copies of these types in teleost fishes (2x pvalb- $\alpha, 2 \mathrm{x}$ pvalb- $\beta 1$, and $5 \mathrm{x}$ pvalb- $\beta 2)$. In most species, the genomic organization suggests the conserved presence of two main genomic clusters (with pvalb- $\beta 1$ and pvalb- $\beta 2$ types), resulting from teleost-specific wholegenome duplication, plus two single-copy pvalb- $\alpha$ types located in different linkage groups. We have further investigated parvalbumin gene expression in the common carp, a species with 21 (19 unique) parvalbumin genes in its genome, and we have identified two pvalb- $\alpha$ and eight pvalb- $\beta 2$ copies abundantly expressed in the muscles, while the alternative copies dominate pvalb expression in other tissues (brain, testes, kidney, retina, and thymus). We have also noticed signs of differential expression of the muscular pvalb- $\beta 2$ copies from the recent whole-genome duplication in this species. We aim to provide robust genomic and transcriptomic evidence of the complex evolution of parvalbumin, which can serve for future studies focused on parvalbumin research.

Supplementary Materials: The following are available online at https: / www.mdpi.com/article/10 .3390/fishes6040070/s1: Table S1: parvalbumin gene expression in the 17 tissues of the common carp (Cyprinus carpio), including the accession numbers for the 70 transcriptomes used; Supplementary Material S2: alignment of 242 sequences used for the phylogenetic tree reconstruction. 
Author Contributions: Conceptualization: Z.M.; methodology: Z.M. and O.B.; analyses: S.M., O.B. and Z.M.; writing—original draft preparation: S.M., K.Z. and Z.M.; writing-review and editing: S.M., K.Z., P.H. (Petr Hanák), P.H. (Petra Horká) and Z.M.; supervision: P.H. (Petr Hanák), P.H. (Petra Horká) and Z.M.; project administration, P.H. (Petr Hanák), K.Z., P.H. (Petra Horká). All authors have read and agreed to the published version of the manuscript.

Funding: This research was funded by the Ministry of Agriculture, Czech Republic, project NAZV QK1910231: New approaches for the proof of fish meat adulteration using genomic DNA.

Institutional Review Board Statement: Not applicable. This research based purely on the data published in the data base.

Data Availability Statement: This manuscript is based on the publicly available data from the GenBank nucleotide, SRA and Genome/Assembly databases. The accession numbers to the data used in this study are available in the Table 1, Supplementary Table S1, and in Figures 1 and 2. The alignment of the sequences selected for the phylogenetic reconstruction is provided as a FASTA file in Supplementary Material S2.

Acknowledgments: We would like to thank Veronika Truhlářová for the FishEvo lab management. We thank three anonymous reviewers for their comments improving the manuscript.

Conflicts of Interest: The authors declare no conflict of interest.

\section{References}

1. Swoboda, I.; Bugajska-Schretter, A.; Valenta, R.; Spitzauer, S.J.A. Recombinant fish parvalbumins: Candidates for diagnosis and treatment of fish allergy. Allergy 2002, 57, 94-96. [CrossRef]

2. Baba, M.L.; Goodman, M.; Berger-Cohn, J.; Demaille, J.G.; Matsuda, G. The early adaptive evolution of calmodulin. Mol. Biol. Evol. 1984, 1, 442-455. [PubMed]

3. Climer, L.K.; Cox, A.M.; Reynolds, T.J.; Simmons, D.D. Oncomodulin: The enigmatic parvalbumin protein. Front. Mol. Neurosci. 2019, 12, 235. [CrossRef]

4. Modrell, M.S.; Lyne, M.; Carr, A.R.; Zakon, H.H.; Buckley, D.; Campbell, A.S.; Davis, M.C.; Micklem, G.; Baker, C.V. Insights into electrosensory organ development, physiology and evolution from a lateral line-enriched transcriptome. eLife 2017, 6, e24197. [CrossRef] [PubMed]

5. Sun, M.; Liang, C.Z.; Gao, H.W.; Lin, C.; Deng, M.J. Detection of parvalbumin, a common fish allergen gene in food, by real-time polymerase chain reaction. J. AOAC Int. 2009, 92, 234-240. [CrossRef] [PubMed]

6. Hanak, P.; Laknerova, I.; Svatora, M. Second intron in the protein-coding region of the fish parvalbumin gene-a promising platform for polymerase chain reaction-based discrimination of fish meat of various species. J. Food Nutr. Res. 2012, 51, 81-88.

7. Abdullah, A.; Rehbein, H. The differentiation of tuna (family: Scombridae) products through the PCR-based analysis of the cytochrome b gene and parvalbumin introns. J. Sci. Food Agric. 2016, 96, 456-464. [CrossRef]

8. Akhatova, D.; Laknerova, I.; Zdenkova, K.; Olafsdottir, G.; Magnusdottir, S.; Piknova, L.; Kyrova, V.; Lerch, Z.; Hanak, P. International interlaboratory study on TaqMan real-time polymerase chain reaction authentication of black seabream (Spondyliosoma cantharus). J. Food Nutr. Res. 2018, 57, 27-37.

9. Friedberg, F. Parvalbumin isoforms in zebrafish. Mol. Biol. Rep. 2005, 32, 167-175. [CrossRef]

10. Berchtold, M.W.; Epstein, P.; Beaudet, A.L.; Payne, M.E.; Heizmann, C.W.; Means, A.R. Structural organization and chromosomal assignment of the parvalbumin gene. J. Biol. Chem. 1987, 262, 8696-8701. [CrossRef]

11. Henrotte, J.G. A crystalline constituent from myogen of carp muscles. Nature 1952, 169, 968-969. [CrossRef]

12. Muntener, M.; Kaser, L.; Weber, J.; Berchtold, M.W. Increase of skeletal-muscle relaxation speed by direct injection of parvalbumin cDNA. Proc. Natl. Acad. Sci. USA 1995, 92, 6504-6508. [CrossRef]

13. Xu, Y.X.; Zhu, Z.Y.; Lo, L.C.; Wang, C.M.; Lin, G.; Feng, F.; Yue, G.H. Characterization of two parvalbumin genes and their association with growth traits in Asian seabass (Lates calcarifer). Anim. Genet. 2006, 37, 266-268. [CrossRef] [PubMed]

14. Rall, J.A. Role of parvalbumin in skeletal muscle relaxation. News Physiol. Sci. 1996, 11, 249-255. [CrossRef]

15. Cuenca, N.; Deng, P.; Linberg, K.A.; Lewis, G.P.; Fisher, S.K.; Kolb, H. The neurons of the ground squirrel retina as revealed by immunostains for calcium binding proteins and neurotransmitters. J. Neurocytol. 2002, 31, 649-666. [CrossRef] [PubMed]

16. Yang, D.; Thalmann, I.; Thalmann, R.; Simmons, D.D. Expression of $\alpha$ and $\beta$ parvalbumin is differentially regulated in the rat organ of corti during development. J. Neurobiol. 2004, 58, 479-492. [CrossRef] [PubMed]

17. Toury, R.; Belqasmi, F.; Hauchecorne, M.; Leguellec, D.; Heizmann, C.W.; Balmain, N. Localization of the Ca ${ }^{2+}-$ binding $\alpha-$ Parvalbumin and its mRNA in epiphyseal plate cartilage and bone of growing rats. Bone 1995, 17, 121-130. [CrossRef]

18. Brewer, J.M.; Arnold, J.; Beach, G.G.; Ragland, W.L.; Wunderlich, J.K. Comparison of the amino acid sequences of tissue-specific parvalbumins from chicken muscle and thymus and possible evolutionary significance. Biochem. Biophys. Res. Commun. 1991, 181, 226-231. [CrossRef]

19. Berchtold, M.W.; Wilson, K.J.; Heizmann, C.W. Isolation of neuronal parvalbumin by high-performance liquid chromatography. Characterization and comparison with muscle parvalbumin. Biochemistry 1982, 21, 6552-6557. [CrossRef] [PubMed] 
20. Berchtold, M.W.; Celio, M.R.; Heizmann, C.W. Parvalbumin in non-muscle tissues of the rat. Quantitation and immunohistochemical localization. J. Biol. Chem. 1984, 259, 5189-5196. [CrossRef]

21. Sanna, P.P.; Keyser, K.T.; Celio, M.R.; Karten, H.J.; Bloom, F.E. Distribution of parvalbumin immunoreactivity in the vertebrate retina. Brain Res. 1993, 600, 141-150. [CrossRef]

22. Griesmeier, U.; Vázquez-Cortés, S.; Bublin, M.; Radauer, C.; Ma, Y.; Briza, P.; Fernández-Rivas, M.; Breiteneder, H. Expression levels of parvalbumins determine allergenicity of fish species. Allergy 2010, 65, 191-198. [CrossRef] [PubMed]

23. Kuehn, A.; Scheuermann, T.; Hilger, C.; Hentges, F. Important variations in parvalbumin content in common fish species: A factor possibly contributing to variable allergenicity. Int. Arch. Allergy Immunol. 2010, 153, 359-366. [CrossRef] [PubMed]

24. Lee, P.W.; Nordlee, J.A.; Koppelman, S.J.; Baumert, J.L.; Taylor, S.L. Measuring parvalbumin levels in fish muscle tissue: Relevance of muscle locations and storage conditions. Food Chem. 2012, 135, 502-507. [CrossRef] [PubMed]

25. Kobayashi, A.; Tanaka, H.; Hamada, Y.; Ishizaki, S.; Nagashima, Y.; Shiomi, K. Comparison of allergenicity and allergens between fish white and dark muscles. Allergy 2006, 61, 357-363. [CrossRef]

26. Lim, D.C.; Neo, K.H.; Goh, D.M.; Shek, L.C.; Lee, B.W. Missing parvalbumin: Implications in diagnostic testing for tuna allergy. J. Allergy Clin. Immunol. 2005, 115, 874-875. [CrossRef] [PubMed]

27. Hilger, C.; Thill, L.; Grigioni, F.; Lehners, C.; Falagiani, P.; Ferrara, A.; Romano, C.; Stevens, W.; Hentges, F. IgE antibodies of fish allergic patients cross-react with frog parvalbumin. Allergy 2004, 59, 653-660. [CrossRef]

28. Van Do, T.; Elsayed, S.; Florvaag, E.; Hordvik, I.; Endresen, C. Allergy to fish parvalbumins: Studies on the cross-reactivity of allergens from 9 commonly consumed fish. J. Allergy Clin. Immunol. 2005, 116, 1314-1320. [CrossRef] [PubMed]

29. Rencova, E.; Kostelnikova, D.; Tremlova, B. Detection of allergenic parvalbumin of Atlantic and Pacific herrings in fish products by PCR. Food Addit. Contam. Part A Chem. Anal. Control Expo. Risk Assess. 2013, 30, 1679-1683. [CrossRef] [PubMed]

30. Lindstrøm, C.D.; van Dô, T.; Hordvik, I.; Endresen, C.; Elsayed, S. Cloning of two distinct cDNAs encoding parvalbumin, the major allergen of Atlantic salmon (Salmo salar). Scand J. Immunol. 1996, 44, 335-344. [CrossRef]

31. Ma, Y.; Griesmeier, U.; Susani, M.; Radauer, C.; Briza, P.; Erler, A.; Bublin, M.; Alessandri, S.; Himly, M.; Breiteneder, H.; et al. Comparison of natural and recombinant forms of the major fish allergen parvalbumin from cod and carp. Mol. Nutr. Food Res. 2008, 52, S196-S207. [CrossRef]

32. Muñoz-Colmenero, M.; Rahman, S.; Martínez, J.L.; Garcia-Vazquez, E. High variability in parvalbumin beta 1 genes offers new molecular options for controlling the mislabeling in commercial Salmonids. Eur. Food Res. Technol. 2019, 245, 1685-1694. [CrossRef]

33. Kretsinger, R.H. Structure and evolution of calcium-modulated protein. CRC Crit. Rev. Biochem. 1980, 8, 119-174. [CrossRef] [PubMed]

34. Goodman, M.; Pechere, J.-F. The evolution of muscular parvalbumins investigated by the Maximum Parsimony method. J. Mol. Evol. 1977, 9, 131-158. [CrossRef] [PubMed]

35. Hapak, R.C.; Zhao, H.; Boschi, J.M.; Henzl, M.T. Novel avian thymic parvalbumin displays high degree of sequence homology to oncomodulin. J. Biol. Chem. 1994, 269, 5288-5296. [CrossRef]

36. Ohno, S. Evolution by Gene Duplication; Springer: New York, NY, USA, 1970.

37. Taylor, J.S.; Van de Peer, Y.; Meyer, A. Genome duplication, divergent resolution and speciation. Trends Genet. 2001, 17, 299-301. [CrossRef]

38. Wagner, A. Birth and death of duplicated genes in completely sequenced eukaryotes. Trends Genet. 2001, 17, 237-239. [CrossRef]

39. Meyer, A.; Schartl, M. Gene and genome duplications in vertebrates: The one-to four (-to-eight in fish) rule and the evolution of novel gene functions. Curr. Opin. Cell Biol. 1999, 11, 699-704. [CrossRef]

40. Zhou, R.; Cheng, H.; Tiersch, T.R. Differential genome duplication and fish diversity. Rev. Fish Biol. Fish. 2002, 11, 331-337. [CrossRef]

41. Meyer, A.; Van de Peer, Y. From 2R to 3R: Evidence for a fish-specific genome duplication (FSGD). Bioessays 2005, 27, 937-945. [CrossRef] [PubMed]

42. Amores, A.; Force, A.; Yan, Y.L.; Joly, L.; Amemiya, C.; Fritz, A.; Ho, R.K.; Langeland, J.; Prince, V.; Wang, Y.L.; et al. Zebrafish hox clusters and vertebrate genome evolution. Science 1998, 282, 1711-1714. [CrossRef]

43. Lemons, D.; McGinnis, W. Genomic evolution of Hox gene clusters. Science 2006, 313, 1918-1922. [CrossRef] [PubMed]

44. Martin, K.J.; Holland, P.W. Diversification of Hox gene clusters in Osteoglossomorph fish in comparison to other teleosts and the spotted gar outgroup. J. Exp. Zool. B Mol. Dev. Evol. 2017, 328, 638-644. [CrossRef]

45. Lien, S.; Koop, B.F.; Sandve, S.R.; Miller, J.R.; Kent, M.P.; Nome, T.; Hvidsten, T.R.; Leong, J.S.; Minkley, D.R.; Zimin, A.; et al. The Atlantic salmon genome provides insights into rediploidization. Nature 2016, 533, 200-205. [CrossRef] [PubMed]

46. Xu, P.; Zhang, X.; Wang, X.; Li, J.; Liu, G.; Kuang, Y.; Xu, J.; Zheng, X.; Ren, L.; Wang, G.; et al. Genome sequence and genetic diversity of the common carp, Cyprinus carpio. Nat. Genet. 2014, 46, 1212-1219. [CrossRef] [PubMed]

47. Du, K.; Stöck, M.; Kneitz, S.; Klopp, C.; Woltering, J.M.; Adolfi, M.C.; Feron, R.; Prokopov, D.; Makunin, A.; Kichigin, I.; et al. The sterlet sturgeon genome sequence and the mechanisms of segmental rediploidization. Nat. Ecol. Evol. 2020, 4, 841-852. [CrossRef] [PubMed]

48. Postlethwait, J.H.; Woods, I.G.; Ngo-Hazelett, P.; Yan, Y.L.; Kelly, P.D.; Chu, F.; Huang, H.; Hill-Force, A.; Talbot, W.S. Zebrafish comparative genomics and the origins of vertebrate chromosomes. Genome Res. 2000, 10, 1890-1902. [CrossRef]

49. Lynch, M.; Force, A. The probability of duplicate gene preservation by subfunctionalization. Genetics 2000, 154, 459-473. [CrossRef]

50. Cortesi, F.; Musilová, Z.; Stieb, S.M.; Hart, N.S.; Siebeck, U.E.; Malmstrøm, M.; Tørresen, O.K.; Jentoft, S.; Cheney, K.L.; Marshall, N.J.; et al. Ancestral duplications and highly dynamic opsin gene evolution in percomorph fishes. Proc. Natl. Acad. Sci. USA 2015, 112, 1493-1498. [CrossRef]

51. Cortesi, F.; Camacho, D.; Luehrmann, M.; Sommer, G.M.; Musilova, Z. Multiple ancestral duplications of the red-sensitive opsin gene (LWS) in teleost fishes and convergent spectral shifts to green vision in gobies. bioRxiv 2021. [CrossRef] 
52. Musilova, Z.; Salzburger, W.; Cortesi, F. The visual opsin gene repertoires of teleost fishes: Evolution, ecology, and function. Annu. Rev. Cell Dev. Biol. 2021, 37, 441-468. [CrossRef]

53. Cheng, C.C.; Chen, L. Evolution of an antifreeze glycoprotein. Nature 1999, 401, 443-444. [CrossRef]

54. Katoh, K.; Standley, D.M. MAFFT multiple sequence alignment software version 7: Improvements in performance and usability. Mol. Biol. Evol. 2013, 30, 772-780. [CrossRef]

55. Katoh, K.; Misawa, K.; Kuma, K.I.; Miyata, T. MAFFT: A novel method for rapid multiple sequence alignment based on fast Fourier transform. Nucleic Acids Res. 2002, 30, 3059-3066. [CrossRef] [PubMed]

56. Huelsenbeck, J.P.; Ronquist, F. MRBAYES: Bayesian inference of phylogenetic trees. Bioinformatics 2001, 17, 754-755. [CrossRef] [PubMed]

57. Ronquist, F; Huelsenbeck, J.P. MrBayes 3: Bayesian phylogenetic inference under mixed models. Bioinformatics 2003, 19, 1572-1574. [CrossRef]

58. FigTree. Available online: http://tree.bio.ed.ac.uk/software/figtree/ (accessed on 31 January 2016).

59. Sayers, E.W.; Barrett, T.; Benson, D.A.; Bolton, E.; Bryant, S.H.; Canese, K.; Clark, K.; Connor, R.; Fiorini, N.; Funk, K.; et al. Database resources of the national center for biotechnology information. Nucleic Acids Res. 2012, 36, D13-D25. [CrossRef] [PubMed]

60. Bushnell, B. BBMap Short-Read Aligner, and Other Bioinformatics Tools; University of California: Berkeley, CA, USA, 2015. Available online: Sourceforge.net/projects/bbmap (accessed on 15 August 2021).

61. Patro, R.; Duggal, G.; Love, M.I.; Irizarry, R.A.; Kingsford, C. Salmon provides fast and bias-aware quantification of transcript expression. Nat. Methods 2017, 14, 417-419. [CrossRef] [PubMed]

62. Liu, W.; Yuan, X.; Yuan, S.; Dai, L.; Dong, S.; Liu, J.; Peng, L.; Wang, M.; Tang, Y.; Xiao, Y. Optimal reference genes for gene expression analysis in polyploid of Cyprinus carpio and Carassius auratus. BMC Genet. 2020, 21, 107. [CrossRef] [PubMed]

63. R Core Team. R: A Language and Environment for Statistical Computing; R Foundation for Statistical Computing: Vienna, Austria, 2020. Available online: https:/ /www.R-project.org/ (accessed on 31 December 2020).

64. Zeileis, A.; Fisher, J.C.; Hornik, K.; Ihaka, R.; McWhite, C.D.; Murrell, P.; Stauffer, R.; Wilke, C.O. Colorspace: A Toolbox for Manipulating and Assessing Colors and Palettes. J. Stat. Softw. 2020, 96, 1-49. [CrossRef]

65. Opazo, J.C.; Butts, G.T.; Nery, M.F.; Storz, J.F.; Hoffmann, F.G. Whole-genome duplication and the functional diversification of teleost fish hemoglobins. Mol. Biol. Evol. 2013, 30, 140-153. [CrossRef] [PubMed]

66. Suzuki, H.; Nikaido, M.; Hagino-Yamagishi, K.; Okada, N. Distinct functions of two olfactory marker protein genes derived from teleost-specific whole genome duplication. BMC Evol. Biol. 2015, 15, 1-13. [CrossRef] [PubMed]

67. Pasquier, J.; Cabau, C.; Nguyen, T.; Jouanno, E.; Severac, D.; Braasch, I.; Journot, L.; Pontarotti, P.; Klopp, C.; Postlethwait, J.H.; et al. Gene evolution and gene expression after whole genome duplication in fish: The PhyloFish database. BMC Genom. 2016, 17, 368. [CrossRef] [PubMed]

68. Gallant, J.R.; Hopkins, C.D.; Deitcher, D.L. Differential expression of genes and proteins between electric organ and skeletal muscle in the mormyrid electric fish Brienomyrus brachyistius. J. Exp. Biol. 2012, 215, 2479-2494. [CrossRef]

69. Shen, Y.; Ma, K.; Zhu, Q.; Xu, X.; Li, J. Transcriptomic analysis reveals growth-related genes in juvenile grass carp, Ctenopharyngodon idella. Aquac. Fish. 2021, in press. [CrossRef]

70. Kaalund, S.S.; Riise, J.; Broberg, B.V.; Fabricius, K.; Karlsen, A.S.; Secher, T.; Plath, N.; Pakkenberg, B. Differential expression of parvalbumin in neonatal phencyclidine-treated rats and socially isolated rats. J. Neurochem. 2013, 124, 548-557. [CrossRef] [PubMed]

71. Filice, F.; Janickova, L.; Henzi, T.; Bilella, A.; Schwaller, B. The parvalbumin hypothesis of autism spectrum disorder. Front. Cell. Neurosci. 2020, 14, 577525. [CrossRef]

72. Hara, E.; Rivas, M.V.; Ward, J.M.; Okanoya, K.; Jarvis, E.D. Convergent differential regulation of parvalbumin in the brains of vocal learners. PLoS ONE 2012, 7, e29457. [CrossRef]

73. Brownridge, P.; de Mello, L.V.; Peters, M.; McLean, L.; Claydon, A.; Cossins, A.R.; Whitfield, P.D.; Young, I.S. Regional variation in parvalbumin isoform expression correlates with muscle performance in common carp (Cyprinus carpio). J. Exp. Biol. 2009, 212, 184-193. [CrossRef] [PubMed]

74. Pérez-Tavarez, R.; Carrera, M.; Pedrosa, M.; Quirce, S.; Rodríguez-Pérez, R.; Gasset, M. Reconstruction of fish allergenicity from the content and structural traits of the component $\beta$-parvalbumin isoforms. Sci. Rep. 2019, 9, 16298. [CrossRef] [PubMed] 